\title{
Coronavirus enzyme inhibitors-experimentally proven natural compounds from plants
}

\author{
Junsoo Park ${ }^{\star}$, Rackhyun Park, Minsu Jang, \\ Yea-In Park, and Yeonjeong Park \\ Division of Biological Science and Technology, Yonsei University, \\ Wonju 26493, Republic of Korea \\ (Received Sep 27, 2021 / Revised Nov 9, 2021 / Accepted Nov 9, 2021)
}

Coronavirus disease (COVID-19) can cause critical conditions that require efficient therapeutics. Several medicines are derived from plants, and researchers are seeking natural compounds to ameliorate the symptoms of COVID-19. Viral enzymes are popular targets of antiviral medicines; the genome of coronaviruses encodes several enzymes, including RNAdependent RNA polymerase and viral proteases. Various screening systems have been developed to identify potential inhibitors. In this review, we describe the natural compounds that have been shown to exert inhibitory effects on coronavirus enzymes. Although computer-aided molecular structural studies have predicted several antiviral compound candidates, the current review focuses on experimentally proven natural compounds.

Keywords: coronavirus, COVID-19, SARS-CoV-2, natural compounds

\section{Introduction}

The Spanish flu pandemic caused 50-100 million deaths worldwide in 1918-1919; approximately 100 years later, the coronavirus disease (COVID-19) pandemic has caused over 4 million deaths in 2019-2021 (Aassve et al., 2021). Although several COVID-19 vaccines have been developed, the appearance of mutant forms has prevented the eradication of severe acute respiratory syndrome coronavirus 2 (SARS-CoV-2) by vaccination (Lopez Bernal et al., 2021; Tregoning et al., 2021). Therefore, the development of antiviral drugs for COVID-19 is urgently needed, and many researchers are seeking medicines that are effective against the disease (Ghosh et al., 2020; Khare et al., 2020). As coronaviruses have been responsible for occasional epidemics causing mild upper respiratory tract illness, SARS-CoV-2 has been predicted to co-exist with hu-

*For correspondence. E-mail: junsoo@yonsei.ac.kr; Tel.: +82-33-760-2560 Copyright (c) 2022, The Microbiological Society of Korea mans for an extended period of time (Rucinski et al., 2020). For this reason, alternative medicines that can alleviate the symptoms of COVID-19 will be welcomed (Nugraha et al., 2020). In this review, we describe natural compounds that have shown an inhibitory effect on coronavirus enzymes. These natural compounds are potentially effective in alleviating COVID-19 symptoms by inhibiting coronavirus infection and replication.

The genomes of most viruses encode enzymes that enable viral replication, and these enzymes are employed as targets for antiviral drugs. The genome of herpesviruses, for example, encodes thymidine kinase, and drugs such as acyclovir have been developed to target thymidine kinase (Pallasch et al., 1984; de Clercq, 1993). The human immunodeficiency virus (HIV) genome encodes reverse transcriptase and protease, and many antiviral drugs have been developed using these enzymes as targets (Collier et al., 1996; Staszewski et al., 1999). Similarly, the hepatitis $\mathrm{C}$ virus genome encodes RNA polymerase and protease, and the combination of these inhibitors can be used to treat HCV infection (Koev et al., 2007; Kwong et al., 2008). Finally, the genome of influenza virus encodes neuraminidase, which is required for virus release, and oseltamivir and zanamivir are popular medicines for the treatment of influenza-related diseases (Jackson et al., 2011; Abed and Boivin, 2017). Coronavirus enzymes are thus popular targets for coronavirus treatment, and many researchers are seeking coronavirus medicines using these enzymes. However, clinically effective inhibitors are not currently available (Pawar, 2020). Natural compounds, especially plant-derived phytochemicals, have a long history of application as a traditional medicine for human health, and many medicines have been derived from natural compounds (Cragg, 2002). Because herbal medicines have been used for a long time, these natural compounds are expected to have relatively low toxicity (Ruhul Amin et al., 2009).

\section{Methods}

This review deals with natural compounds that have shown an inhibitory effect on coronavirus enzymes. Although many studies have predicted the potential inhibitory effects of natural compounds on coronavirus enzymes using computerbased simulations such as docking studies, simulation predictions often differ from experimental results. For example, lopinavir-ritonavir was believed to be effective against SARSCoV-2 3CL-protease; however, experimental results and cli- 
nical studies have shown that lopinavir-ritonavir is effective against neither coronavirus enzymes nor COVID-19 (Nukoolkarn et al., 2008; Cao et al., 2020; Jang et al., 2020b; Ortega et al., 2020; Stower, 2020). For this reason, this review focuses on research results that include laboratory experimental data. In addition, the review excludes the results of natural compound inhibitors with very high half maximal inhibitory concentration $\left(\mathrm{IC}_{50}\right)$ values $\left(\mathrm{IC}_{50}>100 \mu \mathrm{M}\right)$.

\section{Coronavirus Enzymes}

Among the four coronavirus subfamilies (alpha, beta, gamma, and delta), alpha and beta coronavirus subfamilies are known to infect humans (Velavan and Meyer, 2020). SARS-CoV-2, Middle East Respiratory Syndrome (MERS), and SARS-CoV belong to the beta subfamily and cause severe diseases. There are four additional coronaviruses that infect humans, namely,

Table 1. Natural compounds targeting coronavirus 3CL-protease

\begin{tabular}{|c|c|c|c|c|c|}
\hline Botanical name & Plant part & Chemical name & Virus & $\mathrm{IC}_{50}(\mu \mathrm{M})$ & Reference \\
\hline Anacardium occidentale & fruit & anacardic acids & SARS-CoV-2 & 2.07 & Chen et al. (2021) \\
\hline \multirow{7}{*}{ Angelica keiskei } & \multirow{7}{*}{ whole } & isobavachalcone & \multirow{7}{*}{ SARS-CoV } & 39.4 & \multirow{7}{*}{ Park et al. (2016) } \\
\hline & & xanthoangelol & & 38.4 & \\
\hline & & xanthoangelol F & & 34.1 & \\
\hline & & xanthoangelol D & & 26.6 & \\
\hline & & xanthoangelol E & & 11.4 & \\
\hline & & xanthoangelol B & & 22.2 & \\
\hline & & xanthokeistal A & & 44.1 & \\
\hline Betula pubescens & bark & betulinic acid & SARS-CoV & 10 & Wen et al. (2007) \\
\hline \multirow{12}{*}{ Camellia sinensis } & \multirow{12}{*}{ leaf } & \multirow{9}{*}{$\begin{array}{l}\text { epigallocatechin gallate } \\
\text { (EGCG) }\end{array}$} & \multirow{4}{*}{ SARS-CoV-2 } & 16.5 & Jang et al. (2020a) \\
\hline & & & & 4.24 & Chiou et al. (2021) \\
\hline & & & & 7.51 & Zhu and Xie (2020) \\
\hline & & & & 0.874 & Du et al. (2021) \\
\hline & & & \multirow{3}{*}{ SARS-CoV } & 24.98 & Chiou et al. (2021) \\
\hline & & & & $>100$ & Chen et al. (2005) \\
\hline & & & & 73 & Nguyen et al. (2012) \\
\hline & & & $\mathrm{HCoV}-\mathrm{OC} 43$ & 31.8 & Jang et al. (2021) \\
\hline & & & HCoV-229E & 25.5 & Jang et al. (2021) \\
\hline & & \multirow{2}{*}{ theaflavin } & SARS-CoV-2 & 14.9 & Jang et al. (2021) \\
\hline & & & SARS-CoV & 56 & Chen et al. (2005) \\
\hline & & theaflavin-3, $3^{\prime}$-digallate & SARS-CoV & 9.5 & Chen et al. (2005) \\
\hline \multirow{2}{*}{ Cirsium setidens } & \multirow{2}{*}{ flower } & \multirow{2}{*}{ pectolinarin } & SARS-CoV-2 & 51.64 & Jo et al. (2020b) \\
\hline & & & SARS-CoV & 37.78 & Jo et al. (2020a) \\
\hline \multirow{12}{*}{ Ginkgo biloba } & \multirow{12}{*}{ leaf } & ginkgolic acid & \multirow{12}{*}{ SARS-CoV-2 } & 1.79 & Chen et al. (2021) \\
\hline & & ginkgolic acid & & $0.7 \sim 3.57$ & \\
\hline & & genkwanin & & 10.62 & \\
\hline & & quercetin & & 12.65 & \\
\hline & & isorhamnetin & & 31.59 & \\
\hline & & luteolin & & 74.86 & \\
\hline & & apigenin & & 84.94 & Xiong et al. (2021) \\
\hline & & sciadopitysin & & 1.09 & \\
\hline & & ginkgetin & & 2.98 & \\
\hline & & isoginkgetin & & 2.33 & \\
\hline & & amentoflavone & & 8.65 & \\
\hline & & bilobetin & & 11.19 & \\
\hline Isatis indigotica & root & hespretin & SARS-CoV & 8.3 & Lin et al. (2005) \\
\hline Pistacia lentiscus & leaf & 1,2,3,4,6-pentagalloylglucose & SARS-CoV-2 & 3.66 & Chiou et al. (2021) \\
\hline Pterocarpus santalinus & root & savinin & SARS-CoV & 25 & Wen et al. (2007) \\
\hline \multirow{2}{*}{ Rhodiola rosea } & \multirow{2}{*}{ root } & \multirow{2}{*}{ herbacetin } & SARS-CoV-2 & 53.90 & Jo et al. (2020b) \\
\hline & & & SARS-CoV & 33.17 & Jo et al. (2020a) \\
\hline Rhus semialata & fruit & tannic acid & SARS-CoV-2 & 13.4 & Wang et al. (2020) \\
\hline Rhus succedanea & leaf & rhoifolin & SARS-CoV & 27.45 & Jo et al. (2020a) \\
\hline \multirow{4}{*}{ Scutellaria baicalensis } & \multirow{4}{*}{ root } & baicalin & \multirow{4}{*}{ SARS-CoV-2 } & 34.71 & Jo et al. (2020b) \\
\hline & & & & 6.41 & Su et al. (2020b) \\
\hline & & baicalein & & 0.94 & Su et al. (2020b) \\
\hline & & Scutellarin & & 3.02 & Su et al. (2020b) \\
\hline
\end{tabular}


human coronavirus OC43 (HCoV-OC43), HCoV-HKU1, HCoV-229E, and HCoV-NL63 (Rucinski et al., 2020). HCoV$229 \mathrm{E}$ and CoV-NL63 belong to the alpha coronavirus subfamily, and $\mathrm{HCoV}-\mathrm{OC} 43$ and HCoV-HKU1 belong to the beta coronavirus subfamily (Bahadur et al., 2020). Although these coronaviruses share significant homology with SARS$\mathrm{CoV}-2$, they cause mild symptoms. They are thus suitable as model viruses to study SARS-CoV-2 under less strict conditions (Jang et al., 2021).

The genome of coronaviruses, including SARS-CoV-2, encodes several essential enzymes that are required for their replication (Thiel et al., 2003; Ziebuhr, 2004). These enzymes are therefore employed as drug targets for the discovery of novel coronavirus drugs. The most popular enzymes are RNAdependent RNA polymerase (RdRp) and proteases (Ullrich and Nitsche, 2020; Zhu et al., 2020). Because coronaviruses have a single-stranded positive-sense RNA genome (Baltimore class III), their genome encodes an RNA-dependent RNA polymerase for their replication (Gao et al., 2020). As the structure of RNA-dependent RNA polymerase is distinct from that of cellular DNA-dependent RNA polymerase, RNAdependent RNA polymerase is a suitable target for coronavirus drug development (Zhu et al., 2020). Other popular targets are coronavirus proteases. The genomes of many viruses encode polyproteins to minimize the genome size, and these polyproteins are cleaved into individual functional proteins by virus-encoded proteases (Anderson et al., 2009). These viral proteases are therefore essential for virus replication, and specific inhibitors of these proteases are developed into antiviral drugs (Kim et al., 2013). Coronavirus genomes encode two viral proteases, a 3C-like protease (3CL-pro) and a papain-like protease (PL-pro). Because 3CL-pro has 11 cleavage sites in the coronavirus polyprotein and PL protease has four, 3CL-pro is also known as the main protease (Mpro) (Anand et al., 2003; Hsu et al., 2005). Recently, several additional enzymes, such as uridylate-specific endoribonuclease, have been proposed as drug targets for coronavirus therapy (Hong et al., 2021).

\section{CL-protease (3CL-pro)}

3CL-pro is an essential enzyme that cleaves the coronavirus polyprotein at multiple sites; therefore, the inhibition of 3CLpro also inhibits the replication of coronaviruses (Anand $e t$ al., 2003; Hsu et al., 2005). For example, peptide-based competitive inhibitors were tested as inhibitors of SARS-CoV-2 3CL-pro and were found to significantly inhibit SARS-CoV-2 replication (Zhang et al., 2020).

Protease assays are relatively easy to perform using fluorescence resonance energy transfer (FRET)-based systems, and many natural compounds have been thus tested to examine their inhibitory activity (Jo et al., 2020a; Khare et al., 2020). Although many computer-based simulations or docking studies have been performed, we focused on experimental data in this review. Various natural compounds have been identified as inhibitors of 3CL-pro, and assays are usually performed with SARS-CoV-2 and SARS-CoV (Table 1). IC 50 was determined using the 3CL-pro assay and can be used to estimate the relative inhibitory activity.

Extensive studies have been performed with tea catechins, and epigallocatechin gallate (EGCG) and theaflavin have been reported to be effective inhibitors of coronavirus 3CLpro (Chen et al., 2005; Park et al., 2021). Multiple studies have shown that EGCG inhibits SARS-CoV-2 3CL-pro, and the $\mathrm{IC}_{50}$ range of EGCG was found to be $0.847-16.5 \mu \mathrm{M}$ (Jang
(A)
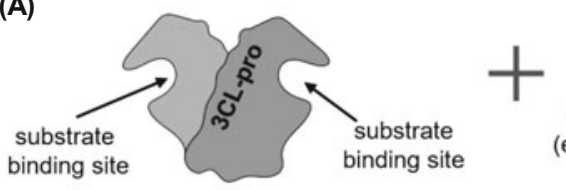

natural compounds (e.g. EGCG, baicalin)

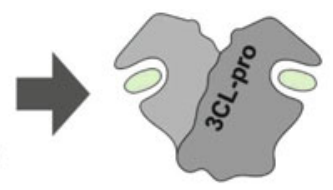

(B)
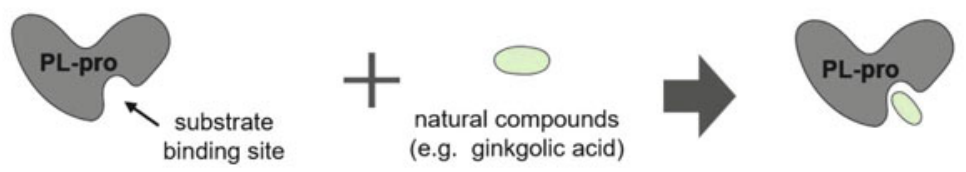

Fig. 1. In silico molecular docking study revealed the potential binding modes of natural compounds to coronavirus proteases. Natural compounds occupy the substrate binding site of coronavirus proteases. (A) 3CL-pro, (B) PL-pro. (C) 3CL-pro structure is shown in cyan, and the potential binding sites of EGCG and baicalin are shown in red. Yellow circle indicates the substrate binding site.
(C)
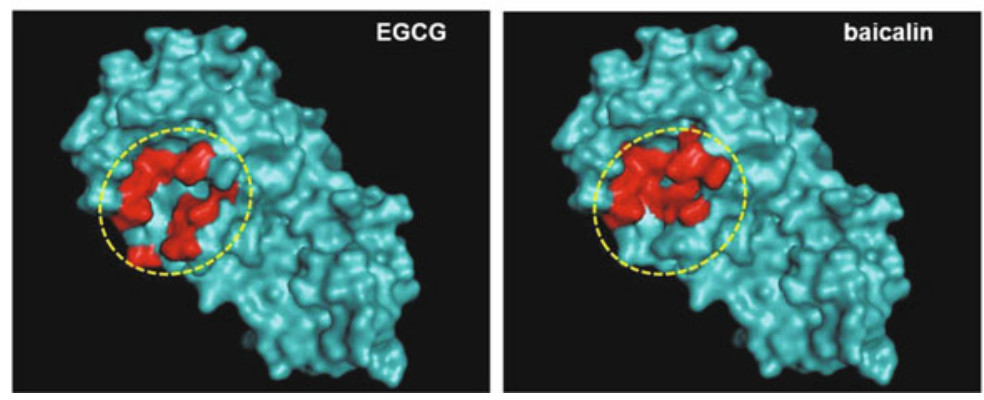
et al., 2020a; Chiou et al., 2021; Du et al., 2021). Interestingly, EGCG has been reported to be more effective against SARSCoV-2 than against SARS-CoV and other human coronaviruses (Chiou et al., 2021; Park et al., 2021). In one study, EGCG was reported to be ineffective against SARS-CoV 3CLpro, with an $\mathrm{IC}_{50}$ of over $100 \mu \mathrm{M}$ (Chen et al., 2005). However, treatment with EGCG has been shown to inhibit the replication of coronavirus in infected cells (Hong et al., 2021; Jang et al., 2021). Because green tea contains a high percentage of EGCG, the relationship between consumption of green tea and COVID-19 morbidity/mortality was studied through an examination of statistical data, and countries with high green tea consumption showed relatively low morbidity/mortality due to COVID-19 (Storozhuk, 2020). Recently, a preliminary clinical study was performed to demonstrate the efficacy of green tea in COVID-19 patients (Bettuzzi et al., 2021).

To identify potential SARS-CoV-2 inhibitors, high-throughput screening of 1920 natural products was performed using SARS-CoV-2 proteases, and ginkgolic acid from Ginkgo biloba and anacardic acid from Anacardium occidentale were identified as effective inhibitors (Chen et al., 2021). Interestingly, both ginkgolic acid and anacardic acid exerted inhibitory effects on both 3CL-pro and PL-pro, and the $\mathrm{IC}_{50}$ value for $3 \mathrm{CL}$-pro was found to be lower than the $\mathrm{IC}_{50}$ of PL-

Table 2. Natural compounds targeting coronavirus PL-protease

\begin{tabular}{|c|c|c|c|c|c|}
\hline Botanical name & Plant part & Chemical name & Virus & $\mathrm{IC}_{50}(\mu \mathrm{M})$ & Reference \\
\hline \multirow{6}{*}{ Alnus japonica } & \multirow{6}{*}{ bark } & hirsutenone & \multirow{6}{*}{ SARS-CoV } & 4.1 & \multirow{6}{*}{ Park et al. (2012) } \\
\hline & & hirsutanonol & & 7.8 & \\
\hline & & oregonin & & 20.1 & \\
\hline & & rubranol & & 12.3 & \\
\hline & & rubranoside B & & 8.0 & \\
\hline & & rubranoside $\mathrm{A}$ & & 9.1 & \\
\hline Anacardium occidentale & fruit & anacardic acids & SARS-CoV-2 & 17.08 & Chen et al. (2021) \\
\hline \multirow{9}{*}{ Angelica keiskei } & \multirow{9}{*}{ leaf } & isobavachalcone & & 13 & \multirow{9}{*}{ Park et al. (2016) } \\
\hline & & 4-hydroxyderricin & & 26 & \\
\hline & & xanthoangelol & & 11.7 & \\
\hline & & xanthoangelol F & & 5.6 & \\
\hline & & xanthoangelol D & SARS-CoV & 19.3 & \\
\hline & & xanthoangelol E & & 1.2 & \\
\hline & & xanthoangelol B & & 11.7 & \\
\hline & & xanthoangelol G & & 46.4 & \\
\hline & & xanthokeistal A & & 21.1 & \\
\hline Curcuma longa & root & curcumin & SARS-CoV & 5.7 & Park et al. (2012) \\
\hline Ginkgo biloba & leaf & Ginkgolic acid & SARS-CoV-2 & 16.30 & Chen et al. (2021) \\
\hline \multirow{12}{*}{ Paulownia tomentosa } & \multirow{12}{*}{ fruit } & tomentin $\mathrm{A}$ & \multirow{12}{*}{ SARS-CoV } & 6.2 & \multirow{12}{*}{ Cho et al. (2013) } \\
\hline & & tomentin B & & 6.1 & \\
\hline & & tomentin C & & 11.6 & \\
\hline & & tomentin D & & 12.5 & \\
\hline & & tomentin $\mathrm{E}$ & & 5.0 & \\
\hline & & 3'-O-methyldiplacol & & 9.5 & \\
\hline & & $4^{\prime}$-O-methyldiplacol & & 9.2 & \\
\hline & & $3^{\prime}$-O-methyldiplacone & & 13.2 & \\
\hline & & $4^{\prime}$-O-methyldiplacone & & 12.7 & \\
\hline & & mimulone & & 14.4 & \\
\hline & & diplacone & & 10.4 & \\
\hline & & $\begin{array}{l}\text { 6-geranyl-4',5,7-trihydroxy- } \\
\text { 3',5'-dimethoxyflavanone }\end{array}$ & & 13.9 & \\
\hline \multirow{6}{*}{ Psoralea corylifolia } & \multirow{6}{*}{ seed } & bavachinin & \multirow{6}{*}{ SARS-CoV } & 38.4 & \multirow{6}{*}{ Kim et al. (2014) } \\
\hline & & neobavaisoflavone & & 18.3 & \\
\hline & & isobavachalcone & & 7.3 & \\
\hline & & $4^{\prime}$-O-methylbavachalcone & & 10.1 & \\
\hline & & psoralidin & & 4.2 & \\
\hline & & corylifol A & & 32.3 & \\
\hline \multirow{6}{*}{ Tribulus terrestris } & \multirow{6}{*}{ fruit } & $N$-trans-caffeoyltyramine & \multirow{6}{*}{ SARS-CoV } & 44.4 & \multirow{6}{*}{ Song et al. (2014) } \\
\hline & & $N$-trans-coumaroyltyramine & & 38.8 & \\
\hline & & $N$-trans-feruloyltyramine & & 70.1 & \\
\hline & & terrestriamide & & 21.5 & \\
\hline & & $N$-trans-feruloyloctopamine & & 26.6 & \\
\hline & & terrestrimine & & 15.8 & \\
\hline
\end{tabular}


pro, indicating that 3CL-pro is more susceptible to ginkgolic acid and anarcardic acid treatment (Chen et al., 2021). In addition, both ginkgolic acid and anacardic acid were effective in reducing the number of SARS-CoV-2 induced plaques (Chen et al., 2021). In another study, a screening of 80 herbal compounds showed that ginkgo extract was effective in inhibiting SARS-CoV-2 3CL-pro, and ginkgolic acid and other natural compounds from ginkgo leaves were identified as the compounds responsible for this inhibition (Xiong et al., 2021).

In a screening of 70 flavonoids, baicalin was identified as an effective inhibitor of SARS-CoV-2 3CL-pro (Jo et al., 2020b). A separate study also revealed that baicalin and baicalein from Scutellaria baicalensis showed inhibitory activity against SARS- CoV-2 3CL-pro (Su et al., 2020b). Moreover, baicalin and baicalein have been found to show inhibitory activity against SARS-CoV-2 RNA-dependent RNA polymerase (Zandi et al., 2021).

Coronavirus 3CL-pro has a substrate binding pocket and catalytic residues, and in silico molecular docking analysis predicted that the natural compounds such as EGCG, ginkgolic acid and baicalin occupy the substrate binding site by forming hydrogen bonds with multiple residues of 3CL-pro (Su et al., 2020; Chen et al., 2021; Chiou et al., 2021; Iketani et al., 2021). These in silico analysis results provide the possible explanation for how the natural compounds inhibit coronavirus 3CL-pro (Fig. 1A and C).

\section{Papain-Like protease (PL-pro)}

The coronavirus genome encodes papain-like protease (PLpro), which cleaves the coronavirus polyprotein (Klemm et al., 2020). PL-pro is also known to remove ubiquitin-like ISG15 protein and Lys48-linked polyubiquitins (Freitas et al., 2020). Because coronavirus PL-pro is an essential enzyme, PL-pro is regarded as an important antiviral target (Klemm et al., 2020). There are several natural compounds that have shown an inhibitory effect on the PL-pro of coronaviruses such as SARS-CoV (Table 2). Currently, the number of publications on SARS-CoV-2 PL-pro is less than that on 3CLpro; because 3CL-pro is regarded as the main protease, initial studies were performed with 3CL-pro.

Alnus japonica is a popular traditional medicine in Korea for the treatment of cancer and hepatitis (Kim et al., 2004; Sati et al., 2011). The ethanol extract of air-dried Alnus japonica bark was used to identify PL-pro inhibitors, and the purified diarylheptanoid exerted an inhibitory effect on SARSCoV PL-pro (Park et al., 2012).

Angelica keiskei mainly grows along the Pacific coast of Japan, where it is also used as a diuretic and tonic (Akihisa et al., 2003). An ethanol extract of Angelica keiskei showed 75\% inhibition of SARS-CoV 3CL-pro and 88\% inhibition of PLpro at $30 \mu \mathrm{g} / \mathrm{ml}$ (Park et al., 2016). Compounds isolated from Angelica keiskei also exerted significant inhibitory effects on both 3CL-pro and PL-pro (Park et al., 2016).

Tribulus terrestris is distributed throughout India and the southern part of China, and its fruits are widely used in pharmaceutical preparations and food supplements (Kostova and Dinchev, 2005). A methanol extract of Tribulus terrestris fruit showed potent inhibition of SARS-CoV PL-pro, and bioactivity-guided purification resulted in the identification of cinnamic amide and ferulic acid as natural compound PL-pro inhibitors (Song et al., 2014).

Paulownia tomentosa is a polyphenol-rich plant that has been used in Chinese traditional medicines (Cho et al., 2013). Consumption of Paulownia tomentosa fruit is known to relieve bronchitis, especially by reducing coughing and asthma (Schneiderová and Šmejkal, 2015). A methanol extract of Paulownia tomentosa fruit was purified to yield natural compounds that showed inhibitory effects on PL-pro, and five novel geranylated flavonoids (tomentin $\mathrm{A}$, tomentin $\mathrm{B}$, tomentin $\mathrm{C}$, tomentin $\mathrm{D}$, and tomentin $\mathrm{E}$ ) were identified as natural compound inhibitors of SARS-CoV PL-pro (Cho et al., 2013).

Coronavirus PL-pro also has a substrate binding site like 3CL-pro, and in silico molecular docking analysis showed the substrate binding pocket was occupied by the natural compounds including ginkgolic acid and xanthoangelol (Park et al., 2016; Chen et al., 2021). These results suggest that the interaction of natural compounds with the substrate binding site of PL-pro contributes to the inhibition of coronavirus PL-pro (Fig. 1B).

\section{RNA-Dependent RNA Polymerase and Other Targets}

Coronaviruses have a single-stranded RNA genome and require RNA-dependent RNA polymerase for replication (Xu et al., 2003). Because several viral RNA-dependent RNA polymerase inhibitors have been developed, these inhibitors have been tested to treat coronavirus diseases (Furuta et al., 2013; Tchesnokov et al., 2019). Clinical results showed that ribavirin and remdesivir have no or limited effects in the treatment of COVID-19 (Beigel et al., 2020; Hung et al., 2020; Tong et al., 2020; Young et al., 2021).

Although coronavirus RNA-dependent RNA polymerase is an attractive target for drug development, the screening system is not as simple as other protease systems (Zandi et al., 2021). For this reason, many inhibitors were tested using insilico methods; however, few studies were performed to screen coronavirus RNA-dependent RNA polymerase. Baicalein and baicalin from Scutellaria baicalensis showed inhibitory effects on coronavirus RNA-dependent RNA polymerase (Zandi et al., 2021). Baicalein and baicalin also exerted an inhibitory effect on the replication of other RNA viruses, including dengue virus and chikungunya virus (Zandi et al., 2012; Moghaddam et al., 2014; Lani et al., 2016).

The SARS-CoV-2 genome encodes uridylate-specific endoribonuclease (non-structural protein 15, Nsp15), and Nsp15 cleaves poly $\mathrm{U}$ sequences of viral RNA intermediates to decrease the level of poly U-containing sequences (Ulferts and Ziebuhr, 2011; Kim et al., 2020). The host innate immune system can recognize the poly $U$ sequence in the viral genome; therefore, Nsp15 can help the virus to evade the host innate immune system (Kindler et al., 2017; Hackbart et al., 2020). EGCG and baicalin have been reported to inhibit the function of Nsp15, and the inhibition of Nsp15 appears to contribute to the inhibition of coronavirus replication (Hong et al., 2021). 


\section{Discussion}

In this review, we summarize the experimental results of coronavirus enzyme inhibitors derived from plants. Because protease assays are relatively easy to perform, many inhibitors have been discovered using coronavirus 3CL-pro and coronavirus PL-pro. Several reports have shown that inhibition of coronavirus replication in cultured cells indicates that these enzyme inhibitors are effective in reducing coronavirus replication in vitro (Chen et al., 2021; Hong et al., 2021; Jang et al., 2021). Because an effective medicine against coronavirus is not available, an approach with natural compounds will be useful in developing effective coronavirus therapies.

Among the list of coronavirus enzyme inhibitors, the efficacy of several compounds was confirmed in multiple studies, and these repeated results make the data more reliable. EGCG, theaflavin, ginkgolic acid, and baicalin have been confirmed as effective inhibitors (Jang et al., 2020a; Jo et al., 2020b; Chen et al., 2021). In addition, several compounds, including ginkgolic acid, anacardic acid, baicalin, and EGCG, target multiple coronavirus enzymes. Further studies should be conducted to determine the major target of these compounds. For example, ginkgolic acid and anacardic acid appear to be more effective against SARS-CoV-2 3CL-pro than against SARS-CoV-2 PLpro because the $\mathrm{IC}_{50}$ of $3 \mathrm{CL}$-pro is notably lower than the IC $_{50}$ of PL-protease (Chen et al., 2021). However, the effect of each enzyme inhibition on the replication of the virus is different, and the inhibitory effect on coronavirus replication cannot be judged simply by the scale of $\mathrm{IC}_{50}$.

Because herbal medicine has been used for a long time, natural compounds from plants or plant extracts are considered relatively safe. For example, green tea has been consumed for thousands of years, and green tea contains a relatively high percentage of EGCG (Park et al., 2021). In the future, preclinical trials including animal experiments and clinical trials should be conducted to validate the efficacy of these natural compounds in vivo.

\section{Acknowledgements}

This study was supported by a National Research Foundation of Korea (NRF) grant funded by the Korean government (2019R1A2C1006511). We tried to include most experimental results of natural compounds acting as coronavirus inhibitors; however, some results may be missing.

\section{Conflict of Interest}

The authors have no conflict of interest to report.

\section{References}

Aassve, A., Alfani, G., Gandolfi, F., and Le Moglie, M. 2021. Epidemics and trust: the case of the Spanish flu. Health Econ. 30, 840-857.

Abed, Y. and Boivin, G. 2017. A review of clinical influenza a and $\mathrm{b}$ infections with reduced susceptibility to both oseltamivir and zanamivir. Open Forum Infect. Dis. 4, ofx105.

Akihisa, T., Tokuda, H., Ukiya, M., Iizuka, M., Schneider, S., Ogasa- wara, K., Mukainaka, T., Iwatsuki, K., Suzuki, T., and Nishino, H. 2003. Chalcones, coumarins, and flavanones from the exudate of Angelica keiskei and their chemopreventive effects. Cancer Lett. 201, 133-137.

Anand, K., Ziebuhr, J., Wadhwani, P., Mesters, J.R., and Hilgenfeld, R. 2003. Coronavirus main proteinase (3CLpro) structure: basis for design of anti-SARS drugs. Science 300, 1763-1767.

Anderson, J., Schiffer, C., Lee, S.K., and Swanstrom, R. 2009. Viral protease inhibitors,. In Kräusslich, H.G. and Bartenschlager, R. (eds.), Antiviral Strategies, Handbook of Experimental Pharmacology, pp. 85-110. Springer Berlin Heidelberg, Berlin, Heidelberg, Germany.

Bahadur, S., Long, W., and Shuaib, M. 2020. Human coronaviruses with emphasis on the COVID-19 outbreak. Virusdisease. 31, 1-5.

Beigel, J.H., Tomashek, K.M., Dodd, L.E., Mehta, A.K., Zingman, B.S., Kalil, A.C., Hohmann, E., Chu, H.Y., Luetkemeyer, A., Kline, S., et al. 2020. Remdesivir for the treatment of Covid-19-final report. N. Engl. J. Med. 383, 1813-1826.

Bettuzzi, S., Gabba, L., and Cataldo, S. 2021. Efficacy of a polyphenolic, standardized green tea extract for the treatment of COVID-19 syndrome: A proof-of-principle study. COVID 1, 2-12.

Cao, B., Wang, Y., Wen, D., Liu, W., Wang, J., Fan, G., Ruan, L., Song, B., Cai, Y., Wei, M., et al. 2020. A trial of lopinavir-ritonavir in adults hospitalized with severe Covid-19. N. Engl. J. Med. 382, 1787-1799.

Chen, Z., Cui, Q., Cooper, L., Zhang, P., Lee, H., Chen, Z., Wang, Y., Liu, X., Rong, L., and Du, R. 2021. Ginkgolic acid and anacardic acid are specific covalent inhibitors of SARS-CoV-2 cysteine proteases. Cell Biosci. 11, 45.

Chen, C.N., Lin, C.P.C., Huang, K.K., Chen, W.C., Hsieh, H.P., Liang, P.H., and Hsu, J.T.A. 2005. Inhibition of SARS-CoV 3C-like protease activity by theaflavin-3,3'-digallate (TF3). Evid. Based Complement. Alternat. Med. 2, 209-215.

Chiou, W.C., Chen, J.C., Chen, Y.T., Yang, J.M., Hwang, L.H., Lyu, Y.S., Yang, H.Y., and Huang, C. 2021. The inhibitory effects of PGG and EGCG against the SARS-CoV-2 3C-like protease. Biochem. Biophys. Res. Commun. doi: https://doi.org/10.1016/j.bbrc. 2020.12.106.

Cho, J.K., Curtis-Long, M.J., Lee, K.H., Kim, D.W., Ryu, H.W., Yuk, H.J., and Park, K.H. 2013. Geranylated flavonoids displaying SARS-CoV papain-like protease inhibition from the fruits of Paulownia tomentosa. Bioorg. Med. Chem. 21, 3051-3057.

Collier, A.C., Coombs, R.W., Schoenfeld, D.A., Bassett, R.L., Timpone, J., Baruch, A., Jones, M., Facey, K., Whitacre, C., McAuliffe, V.J., et al. 1996. Treatment of human immunodeficiency virus infection with saquinavir, zidovudine, and zalcitabine. N. Engl. J. Med. 334, 1011-1018.

Cragg, G.M. 2002. Natural product drug discovery and development: The United States National Cancer Institute role. P. R. Health Sci. J. 21, 97-111.

De Clercq, E. 1993. Antivirals for the treatment of herpesvirus infections. J. Antimicrob. Chemother. 32, 121-132.

Du, A., Zheng, R., Disoma, C., Li, S., Chen, Z., Li, S., Liu, P., Zhou, Y., Shen, Y., Liu, S., et al. 2021. Epigallocatechin-3-gallate, an active ingredient of Traditional Chinese Medicines, inhibits the 3CLpro activity of SARS-CoV-2. Int. J. Biol. Macromol. 176, 1-12.

Freitas, B.T., Durie, I.A., Murray, J., Longo, J.E., Miller, H.C., Crich, D., Hogan, R.J., Tripp, R.A., and Pegan, S.D. 2020. Characterization and noncovalent inhibition of the deubiquitinase and deisgylase activity of SARS-CoV-2 papain-like protease. ACS Infect. Dis. 6, 2099-2109.

Furuta, Y., Gowen, B.B., Takahashi, K., Shiraki, K., Smee, D.F., and Barnard, D.L. 2013. Favipiravir (T-705), a novel viral RNA polymerase inhibitor. Antiviral Res. 100, 446-454.

Gao, Y., Yan, L., Huang, Y., Liu, F., Zhao, Y., Cao, L., Wang, T., Sun, Q., Ming, Z., Zhang, L., et al. 2020. Structure of the RNA-dependent RNA polymerase from COVID-19 virus. Science 368, 
779-782.

Ghosh, A.K., Brindisi, M., Shahabi, D., Chapman, M.E., and Mesecar, A.D. 2020. Drug development and medicinal chemistry efforts toward SARS-coronavirus and Covid-19 therapeutics. ChemMedChem. 15, 907-932.

Hackbart, M., Deng, X., and Baker, S.C. 2020. Coronavirus endoribonuclease targets viral polyuridine sequences to evade activating host sensors. Proc. Natl. Acad. Sci. USA 117, 8094-8103.

Hong, S., Seo, S.H., Woo, S.J., Kwon, Y., Song, M., and Ha, N.C. 2021. Epigallocatechin gallate inhibits the uridylate-specific endoribonuclease Nsp15 and efficiently neutralizes the SARS-CoV-2 strain. J. Agric. Food Chem. 69, 5948-5954.

Hsu, M.F., Kuo, C.J., Chang, K.T., Chang, H.C., Chou, C.C., Ko, T.P., Shr, H.L., Chang, G.G., Wang, A.H.J., and Liang, P.H. 2005. Mechanism of the maturation process of SARS-CoV 3CL protease. J. Biol. Chem. 280, 31257-31266.

Hung, I.F.N., Lung, K.C., Tso, E.Y.K., Liu, R., Chung, T.W.H., Chu, M.Y., Ng, Y.Y., Lo, J., Chan, J., Tam, A.R., et al. 2020. Triple combination of interferon beta-1b, lopinavir-ritonavir, and ribavirin in the treatment of patients admitted to hospital with COVID-19: An open-label, randomised, phase 2 trial. Lancet 395, 1695-1704.

Iketani, S., Forouhar, F., Liu, H., Hong, S.J., Lin, F.Y., Nair, M.S., Zask, A., Huang, Y., Xing, L., Stockwell, B.R., et al. 2021. Lead compounds for the development of SARS-CoV-2 3CL protease inhibitors. Nat. Commun. 12, 2016.

Jackson, R.J., Cooper, K.L., Tappenden, P., Rees, A., Simpson, E.L., Read, R.C., and Nicholson, K.G. 2011. Oseltamivir, zanamivir and amantadine in the prevention of influenza: a systematic review. J. Infect. 62, 14-25.

Jang, M., Park, Y.I., Cha, Y.E., Park, R., Namkoong, S., Lee, J.I., and Park, J. 2020a. Tea polyphenols EGCG and theaflavin inhibit the activity of SARS-CoV-2 3CL-protease in vitro. Evid. Based Complement. Alternat. Med. 2020, 5630838.

Jang, M., Park, Y.I., Park, R., Cha, Y.E., Namkoong, S., Lee, J.I., and Park, J. 2020b. Lopinavir-ritonavir is not an effective inhibitor of the main protease activity of SARS-CoV-2 in vitro. bioRxiv. doi: https://doi.org/10.1101/2020.09.16.299800.

Jang, M., Park, R., Park, Y.I., Cha, Y.E., Yamamoto, A., Lee, J.I., and Park, J. 2021. EGCG, a green tea polyphenol, inhibits human coronavirus replication in vitro. Biochem. Biophys. Res. Commun. $547,23-28$.

Jo, S., Kim, S., Kim, D.Y., Kim, M.S., and Shin, D.H. 2020a. Flavonoids with inhibitory activity against SARS-CoV-2 3CLpro. J. Enzyme Inhib. Med. Chem. 35, 1539-1544.

Jo, S., Kim, S., Shin, D.H., and Kim, M.S. 2020b. Inhibition of SARSCoV-2 3CL protease by flavonoids. J. Enzyme Inhib. Med. Chem. 35, 145-151.

Khare, P., Sahu, U., Pandey, S.C., and Samant, M. 2020. Current approaches for target-specific drug discovery using natural compounds against SARS-CoV-2 infection. Virus Res. 290, 198169.

Kim, Y., Jedrzejczak, R., Maltseva, N.I., Wilamowski, M., Endres, M., Godzik, A., Michalska, K., and Joachimiak, A. 2020. Crystal structure of Nsp15 endoribonuclease NendoU from SARS-CoV-2. Protein Sci. 29, 1596-1605.

Kim, S.T., Kim, J.D., Ahn, S.H., Ahn, G.S., Lee, Y.I., and Jeong, Y.S. 2004. Hepatoprotective and antioxidant effects of Alnus japonica extracts on acetaminophen-induced hepatotoxicity in rats. Phytother. Res. 18, 971-975.

Kim, Y., Mandadapu, S.R., Groutas, W.C., and Chang, K.O. 2013. Potent inhibition of feline coronaviruses with peptidyl compounds targeting coronavirus 3C-like protease. Antiviral Res. 97, 161-168.

Kim, D.W., Seo, K.H., Curtis-Long, M.J., Oh, K.Y., Oh, J.W., Cho, J.K., Lee, K.H., and Park, K.H. 2014. Phenolic phytochemical displaying SARS-CoV papain-like protease inhibition from the seeds of Psoralea corylifolia. J. Enzyme Inhib. Med. Chem. 29, 59-63.

Kindler, E., Gil-Cruz, C., Spanier, J., Li, Y., Wilhelm, J., Rabouw,
H.H., Züst, R., Hwang, M., V'Kovski, P., Stalder, H., et al. 2017. Early endonuclease-mediated evasion of RNA sensing ensures efficient coronavirus replication. PLoS Pathog. 13, e1006195.

Klemm, T., Ebert, G., Calleja, D.J., Allison, C.C., Richardson, L.W., Bernardini, J.P., Lu, B.G.C., Kuchel, N.W., Grohmann, C., Shibata, Y., et al. 2020. Mechanism and inhibition of the papain-like protease, PLpro, of SARS-CoV-2. EMBO J. 39, e106275.

Koev, G., Dekhtyar, T., Han, L., Yan, P., Ng, T.I., Lin, C.T., Mo, H., and Molla, A. 2007. Antiviral interactions of an HCV polymerase inhibitor with an HCV protease inhibitor or interferon in vitro. Antiviral Res. 73, 78-83.

Kostova, I. and Dinchev, D. 2005. Saponins in Tribulus terrestris chemistry and bioactivity. Phytochem. Rev. 4, 111-137.

Kwong, A.D., McNair, L., Jacobson, I., and George, S. 2008. Recent progress in the development of selected hepatitis $\mathrm{C}$ virus NS3.4A protease and NS5B polymerase inhibitors. Curr. Opin. Pharmacol. 8, 522-531.

Lani, R., Hassandarvish, P., Shu, M.H., Phoon, W.H., Chu, J.J.H., Higgs, S., Vanlandingham, D., Abu Bakar, S., and Zandi, K. 2016. Antiviral activity of selected flavonoids against chikungunya virus. Antiviral Res. 133, 50-61.

Lin, C.W., Tsai, F.J., Tsai, C.H., Lai, C.C., Wan, L., Ho, T.Y., Hsieh, C.C., and Chao, P.D.L. 2005. Anti-SARS coronavirus 3C-like protease effects of Isatis indigotica root and plant-derived phenolic compounds. Antiviral Res. 68, 36-42.

Lopez Bernal, J., Andrews, N., Gower, C., Gallagher, E., Simmons, R., Thelwall, S., Stowe, J., Tessier, E., Groves, N., Dabrera, G., et al. 2021. Effectiveness of Covid-19 vaccines against the B.1.617.2 (delta) variant. N. Engl. J. Med. 385, 585-594.

Moghaddam, E., Teoh, B.T., Sam, S.S., Lani, R., Hassandarvish, P., Chik, Z., Yueh, A., Abubakar, S., and Zandi, K. 2014. Baicalin, a metabolite of baicalein with antiviral activity against dengue virus. Sci. Rep. 4, 5452.

Nguyen, T.T.H., Woo, H.J., Kang, H.K., Nguyen, V.D., Kim, Y.M., Kim, D.W., Ahn, S.A., Xia, Y., and Kim, D. 2012. Flavonoid-mediated inhibition of SARS coronavirus 3C-like protease expressed in Pichia pastoris. Biotechnol. Lett. 34, 831-838.

Nugraha, R.V., Ridwansyah, H., Ghozali, M., Khairani, A.F., and Atik, N. 2020. Traditional herbal medicine candidates as complementary treatments for COVID-19: a review of their mechanisms, pros and cons. Evid. Based Complement. Alternat. Med. 2020, 2560645.

Nukoolkarn, V., Lee, V.S., Malaisree, M., Aruksakulwong, O., and Hannongbua, S. 2008. Molecular dynamic simulations analysis of ritronavir and lopinavir as SARS-CoV 3CL ${ }^{\text {pro }}$ inhibitors. $J$. Theor. Biol. 254, 861-867.

Ortega, J.T., Serrano, M.L., Pujol, F.H., and Rangel, H.R. 2020. Unrevealing sequence and structural features of novel coronavirus using in silico approaches: The main protease as molecular target. EXCLI J. 19, 400-409.

Pallasch, T.J., Joseph, C.E., and Gill, C.J. 1984. Acyclovir and herpesvirus infections: a review of the literature. Oral Surg. Oral. Med. Oral. Pathol. 57, 41-44.

Park, J.Y., Ko, J.A., Kim, D.W., Kim, Y.M., Kwon, H.J., Jeong, H.J., Kim, C.Y., Park, K.H., Lee, W.S., and Ryu, Y.B. 2016. Chalcones isolated from Angelica keiskei inhibit cysteine proteases of SARSCoV. J. Enzyme Inhib. Med. Chem. 31, 23-30.

Park, J.Y., Jeong, H.J., Kim, J.H., Kim, Y.M., Park, S.J., Kim, D., Park, K.H., Lee, W.S., and Ryu, Y.B. 2012. Diarylheptanoids from Alnus japonica inhibit papain-like protease of severe acute respiratory syndrome coronavirus. Biol. Pharm. Bull. 35, 2036-2042.

Park, J., Park, R., Jang, M., and Park, Y.I. 2021. Therapeutic potential of EGCG, a green tea polyphenol, for treatment of coronavirus diseases. Life 11, 197.

Pawar, A.Y. 2020. Combating devastating COVID-19 by drug repurposing. Int. J. Antimicrob. Agents 56, 105984.

Rucinski, S.L., Binnicker, M.J., Thomas, A.S., and Patel, R. 2020. 
Seasonality of coronavirus 229E, HKU1, NL63, and OC43 from 2014 to 2020. Mayo Clin. Proc. 95, 1701-1703.

Ruhul Amin, A.R.M., Kucuk, O., Khuri, F.R., and Shin, D.M. 2009. Perspectives for cancer prevention with natural compounds. J. Clin. Oncol. 27, 2712-2725.

Sati, S.C., Sati, N., and Sati, O.P. 2011. Bioactive constituents and medicinal importance of genus Alnus. Pharmacogn. Rev. 5, 174-183.

Schneiderová, K. and Šmejkal, K. 2015. Phytochemical profile of Paulownia tomentosa (Thunb). Steud. Phytochem. Rev. 14, 799833.

Song, Y.H., Kim, D.W., Curtis-Long, M.J., Yuk, H.J., Wang, Y., Zhuang, N., Lee, K.H., Jeon, K.S., and Park, K.H. 2014. Papainlike protease (PLpro) inhibitory effects of cinnamic amides from Tribulus terrestris fruits. Biol. Pharm. Bull. 37, 1021-1028.

Staszewski, S., Morales-Ramirez, J., Tashima, K.T., Rachlis, A., Skiest, D., Stanford, J., Stryker, R., Johnson, P., Labriola, D.F., Farina, D., et al. 1999. Efavirenz plus zidovudine and lamivudine, efavirenz plus indinavir, and indinavir plus zidovudine and lamivudine in the treatment of HIV-1 infection in adults. N. Engl. J. Med. 341, $1865-1873$.

Storozhuk, M. 2020. Covid-19: could green tea catechins reduce the risks? medRxiv. doi: https://doi.org/10.1101/2020.10.23.20218479.

Stower, H. 2020. Lopinavir-ritonavir in severe COVID-19. Nat. Med. 26, 465.

Su, H., Yao, S., Zhao, W., Li, M., Liu, J., Shang, W., Xie, H., Ke, C., Gao, M., Yu, K., et al. 2020a. Discovery of baicalin and baicalein as novel, natural product inhibitors of SARS-CoV-2 3CL protease in vitro. bioRxiv. doi: https://doi.org/10.1101/2020.04.13. 038687.

Su, H., Yao, S., Zhao, W., Li, M., Liu, J., Shang, W., Xie, H., Ke, C., Hu, H., Gao, M., et al. 2020. Anti-SARS-CoV-2 activities in vitro of Shuanghuanglian preparations and bioactive ingredients. Acta Pharmacol. Sin. 41, 1167-1177.

Tchesnokov, E.P., Feng, J.Y., Porter, D.P., and Götte, M. 2019. Mechanism of inhibition of Ebola virus RNA-dependent RNA polymerase by remdesivir. Viruses 11, 326.

Thiel, V., Ivanov, K.A., Putics, Á., Hertzig, T., Schelle, B., Bayer, S., Weißbrich, B., Snijder, E.J., Rabenau, H., Doerr, H.W., et al. 2003. Mechanisms and enzymes involved in SARS coronavirus genome expression. J. Gen. Virol. 84, 2305-2315.

Tong, S., Su, Y., Yu, Y., Wu, C., Chen, J., Wang, S., and Jiang, J. 2020. Ribavirin therapy for severe COVID-19: a retrospective cohort study. Int. J. Antimicrob. Agents 56, 106114.

Tregoning, J.S., Flight, K.E., Higham, S.L., Wang, Z., and Pierce, B.F. 2021. Progress of the COVID-19 vaccine effort: Viruses, vaccines and variants versus efficacy, effectiveness and escape. Nat. Rev. Immunol. 21, 626-636.
Ulferts, R. and Ziebuhr, J. 2011. Nidovirus ribonucleases: structures and functions in viral replication. RNA Biol. 8, 295-304.

Ullrich, S. and Nitsche, C. 2020. The SARS-CoV-2 main protease as drug target. Bioorg. Med. Chem. Lett. 30, 127377.

Velavan, T.P. and Meyer, C.G. 2020. The COVID-19 epidemic. Trop. Med. Int. Health 25, 278-280.

Wang, S.C., Chen, Y., Wang, Y.C., Wang, W.J., Yang, C.S., Tsai, C.L., Hou, M.H., Chen, H.F., Shen, Y.C., and Hung, M.C. 2020. Tannic acid suppresses SARS-CoV-2 as a dual inhibitor of the viral main protease and the cellular TMPRSS2 protease. Am. J. Cancer Res. 10, 4538-4546.

Wen, C.C., Kuo, Y.H., Jan, J.T., Liang, P.H., Wang, S.Y., Liu, H.G., Lee, C.K., Chang, S.T., Kuo, C.J., Lee, S.S., et al. 2007. Specific plant terpenoids and lignoids possess potent antiviral activities against severe acute respiratory syndrome coronavirus. J. Med. Chem. 50, 4087-4095.

Xiong, Y., Zhu, G.H., Wang, H.N., Hu, Q., Chen, L.L., Guan, X.Q., Li, H.L., Chen, H.Z., Tang, H., and Ge, G.B. 2021. Discovery of naturally occurring inhibitors against SARS-CoV-2 $3 \mathrm{CL}^{\text {pro }}$ from Ginkgo biloba leaves via large-scale screening. Fitoterapia 152, 104909.

Xu, X., Liu, Y., Weiss, S., Arnold, E., Sarafianos, S.G., and Ding, J. 2003. Molecular model of SARS coronavirus polymerase: implications for biochemical functions and drug design. Nucleic Acids Res. 31, 7117-7130.

Young, B., Tan, T.T., and Leo, Y.S. 2021. The place for remdesivir in COVID-19 treatment. Lancet Infect. Dis. 21, 20-21.

Zandi, K., Musall, K., Oo, A., Cao, D., Liang, B., Hassandarvish, P., Lan, S., Slack, R.L., Kirby, K.A., Bassit, L., et al. 2021. Baicalein and baicalin inhibit SARS-CoV-2 RNA-dependent-RNA polymerase. Microorganisms. 9, 893.

Zandi, K., Teoh, B.T., Sam, S.S., Wong, P.F., Mustafa, M.R., and Abubakar, S. 2012. Novel antiviral activity of baicalein against dengue virus. BMC Complement. Altern. Med. 12, 214.

Zhang, L., Lin, D., Sun, X., Curth, U., Drosten, C., Sauerhering, L., Becker, S., Rox, K., and Hilgenfeld, R. 2020. Crystal structure of SARS-CoV-2 main protease provides a basis for design of improved a-ketoamide inhibitors. Science 368, 409-412.

Zhu, W., Chen, C.Z., Gorshkov, K., Xu, M., Lo, D.C., and Zheng, W. 2020. RNA-dependent RNA polymerase as a target for COVID-19 drug discovery. SLAS Discov. 25, 1141-1151.

Zhu, Y. and Xie, D.Y. 2020. Docking characterization and in vitro inhibitory activity of flavan-3-ols and dimeric proanthocyanidins against the main protease activity of SARS-CoV-2. Front. Plant Sci. 11, 601316 .

Ziebuhr, J. 2004. Molecular biology of severe acute respiratory syndrome coronavirus. Curr. Opin. Microbiol. 7, 412-419. 